\title{
Determinants of transgender job satisfaction: Measuring the validity and reliability of the constructs
}

\author{
Adnan Yousuf* \\ Naveed R. Khan**
}

\begin{abstract}
The purpose of this study is to establish as well as examine the validity and reliability of the instrument to measure the perception of working transgender job satisfaction. The instrument was adopted and adapted from the authentic sources and was distributed among 48 working transgender. The content and face validity was analyzed by experts of field and internal construct validity was measured. The reliability of instrument was measured by internal consistent reliability through alpha coefficient along with intra-class correlation coefficients. Construct validity was measured by analyzing convergent and discriminant validity. Moreover, criterionrelated validity was measured through correlation coefficients and internal construct validity was also analyzed by inter-item correlations and co-variances. The inter-item correlation for the variables used in the study shows each item of the study correlates to all other items. All the items correlate with one another, though there are some lower values as well representing that those items have low correlation with each other but are considered acceptable. Statistical analysis suggested that test measures for constructs are reliable with the researchers' comprehension of the nature of factors. All items met the level of acceptability. Hence the results suggested that adapted instrument is valid and reliable in context of the social lab selected in Pakistan and a large scale analysis can be done though this instrument.
\end{abstract}

Keywords: Transgender, management support, validity, reliability, job satisfaction

* M.Phil Scholar, Department of Management Sciences, Bahria University, Karachi

** Assistant Professor, Department of Management Sciences, Bahria University, Karachi 


\section{Introduction}

Human resource and diversity management researchers and practitioners consider sexual orientation and gender diversity as impediment (Ozturk \& Tatli, 2016). Holman, Fish, Oswald, \& Goldberg (2018) conducted study in which it was found that organization in which employees create a cohesive environment and admire sexual minority segment working there and their distinguished viewpoint and experience, as a result this segment produce performance seven times that surpass less heterogeneous group. Organizational environment is essential for sexually diverse workers that affect their performance and wellbeing due to either presence of aggressive behavior or contrary, collaborative conduct. There is surge in working transgender employees that impart notable share in working class (Webster, Adams, Maranto, Sawyer, \& Thoroughgood, 2018). The estimates of gender non conformity workers at workplace from global perspective and the prevalence of unfairness against them proposed that organizations would oversight in capturing the potential and productive labor force from this segment provided that the attention is not paid to make the organizational atmosphere conducive, favorable and cooperative work environment for stigmatized workers (Clise, 2012). Trans-individuals confront enormous occupational issues in all over the world. It was reported in study on sexual orientation and gender identity unfairness at workplace that trans-people face the greatest level of discrimination at work (ILO, 2013). Sexually oriented individuals around the world facing human rights abuses (United Nations, 2016). However, sexual minorities are often subjected to unjust workplace environment, abuse of rights, and prejudice (Gacilo et al., 2018). Oppressing trans-voices at workplace has repercussions for both transindividuals and organization (Alexandra Beauregard, Arevshatian, Booth, \& Whittle, 2018). Transgender workers face myriad of issues at workplace, experts and practitioners show inadequacy in determining the needs of transgender workers as well as devoid of organizational support in recognizing the necessity at workplace. It is evident that the discrimination issues are related to profession and working patterns (Ozturk \& Tatli, 2016). Past research reported that gender non-conforming workers suffer from acute mistreatment at workplace that ensue self-protective measures to avoid persecution (Grant, 2015). Employees get support from their supervisors and organization. Significantly, organization support fosters workers' performance and positively influence work effectiveness (Islam, Khan, Ahmad, \& Ahmed, 2014). Workforce diversity got much attention scientifically because of insufficient literature on trans-employees as 
compare to other groups of workforce diversity (Köllen, 2016). The studies on diversity with different organizational factors explains that heterogeneous group generate novel ideas, bring innovation and expose unique perspective that benefits both organizations and diverse workers (Tran, Garcia-Prieto, \& Schneider, 2011; Zanoni, Janssens, Benschop, \& Nkomo, 2010).

This study aims to test the validity and reliability of the questionnaires. Study initially executed in order to assess the workable implementation of working transgender job satisfaction. A well-established instrument accurately assesses any defined variable then it is considered a valid instrument for that particular variable. An instrument is valid when it is measuring what is claimed to measure (Muijs, 2010). Validity can be categorized as; face validity, criterion validity, content validity and construct validity (Jackson, 2015; Muijs, 2010). Face validity can be defined as whether the test is valid or not apparently (Jackson, 2015). Criterion validity is demonstrated in the actual study to develop its requirement. It entails a good knowledge of theory relating to the concept and a measure of the relationship between measure and factors (Muijs, 2010).Whereas, content validity is used to assess the content of items, whether it measures the concept being measured in the study. Finally, the construct validity is used to check an instrument in order to accurately measure a theoretical construct that it is designed to measure. Moreover, reliability, on the other hand, checks which test scores are free from measurement error (Muijs, 2010). Reliability concerns with a measurement of a phenomenon that provides stable and consistent results (Wilson, 2010).It is a measure of stability or internal consistency of an instrument measuring certain concepts (Jackson, 2015).

\section{Research Method}

The survey was developed and pretested on sample of 48 transgender respondents who were employed. The pretest was employed to make sure accuracy, pretesting of instruments, and choose items. The questionnaire adopted in this study was based on the comprehensive literature review. The questionnaire is divided into two sections with a total of 51 questions. The questionnaire includes the demographic information and the dimension of national culture dimensions, perceived organizational support (POS), discretionary power (DP), leader member exchange (LMX), and job satisfaction. This study is cross-sectional, field survey was used to collect 
data. Non-probability, snowball sampling technique was used for approaching the respondents. This study used seven point choices Likert scale ranges from 1 (Strongly Disagree) to 7 (Strongly Agree) to measure the items. Statistical analysis were performance using, internal consistency through Cronbach alpha along with intra-class correlation coefficient, internal construct validity through inter-item correlations and co-variances, criterion related validity through correlation coefficient. Content and face validity were also examined prior to the data collection. SPSS version 23 was used for statistical analysis.

\section{Results and Analysis}

\subsection{Face and content validity}

One of the types of validity is face validity. It is a subjective and superficial assessment of whether the measurement use in a study appears to be a valid measure of a given variable or construct. It is also called surface validity or appearance validity. Whereas, content validity refers to how adequately measurement tool taps into the various aspects of the particular construct in question. One should consult with the experts in the field and seek a consensus of judgment in order to establish content validity. Content validity measurement entails certain amount of subjectivity. In order to evaluate the face validity and content validity for this study, two field experts were requested and given the research tool and related articles to examine the face validity and content validity and asked to give their expert opinion for better understandability of the questionnaire. It looks at the aspects of the questionnaire in terms of understandability, content appropriateness, and consistency of style, feasibility, formatting enhancing clarity, content appropriateness, readability, and the clarity of language used. Experts were requested to amend and improve the items of questionnaire if necessary. Moreover, they were also requested to revise the items that were incomprehensible and required improvement. The items were validated by the experts.

\subsection{Construct validity and reliability}

To measure the construct validity and reliability the tests of inter-item correlations and co-variances, internal consistency through Cronbach alpha and intra class correlation coefficient, criterion related validity through correlation coefficient, were employed and are presented below. 


\subsubsection{Reliability of variables}

Results of Cronbach's alpha shows that the survey items confirm the reliability level since the values are above 0.7 and one is close to 0.7 which shows excellent internal consistency (Šerbetar \& Sedlar, 2016). Except national Culture Dimension that is 0.675 , this score was reached after excluding three items from this variable due to poor item score. The reliability after excluding those items was 0.675 that is close to 0.7 whereas standard alpha value stands at 0.771 and might be increased with the increase in respondents. The reliability test results mentioned in table 1 showed that the scores of variables meet the level of acceptability. According to Sekaran (2003) the instrument shall be acceptable for research when the alpha value is equal or greater than 0.7 .

Table 1: Reliability score

\begin{tabular}{|l|l|l|}
\hline Variable culture & $\begin{array}{l}\text { Cronbach's } \\
\text { Alpha }\end{array}$ & $\begin{array}{l}\text { No } \\
\text { items }\end{array}$ \\
\hline $\begin{array}{l}\text { National } \\
\text { dimensions }\end{array}$ & 16 \\
\hline $\begin{array}{l}\text { Perceived organizational } \\
\text { support }\end{array}$ & 0.811 & 4 \\
\hline Leader-member exchange & 0.930 & 11 \\
\hline Discretionary power job & 0.729 & 12 \\
\hline $\begin{array}{l}\text { Transgender } \\
\text { satisfaction }\end{array}$ & 0.735 & 5 \\
\hline
\end{tabular}

\subsubsection{Intra class correlation coefficient}

It determines the reliability of measurements or ratings. It shows the set of coefficients that represents the relationship between variables of the same class. This intra class correlation coefficients the most interested area for internal reliability that analyze average measures that should be above 0.7. The value less than 0.5 shows poor rating reliability, value ranging from 0.5 to 0.75 shows moderate reliability of rating, value lies within 0.75 to 0.9 indicates good rating reliability and the values more than 0.9 are considered excellent rating reliability. Confidence interval at the lower limit and upper limit of average measures range from 0.7 to 0.8 shows moderate to good whereas above 0.8 to 0.9 shows good to excellent. ICC at $95 \%$ confidence 
intervals was calculated by using SPSS statistical package version 23 based on a mean rating $(\mathrm{k}=3)$, absolute agreement, 2 -waymixed-effects model.

Table 2: Intra-class Correlation Coefficient

\begin{tabular}{|l|l|r|r|}
\hline Variable & \multicolumn{1}{|c|}{ Measure } & $\begin{array}{c}\text { Intra-class } \\
\text { Correlation }\end{array}$ & \multicolumn{1}{c|}{ Sig } \\
\hline \multirow{2}{*}{ National Culture } & Single Measures & $.115^{\mathrm{a}}$ & .000 \\
\cline { 2 - 4 } & Average Measures & $.675^{\mathrm{c}}$ & .000 \\
\hline $\begin{array}{l}\text { Perceived Organizationa } \\
\text { Support }\end{array}$ & Single Measures & $.471^{\mathrm{a}}$ & .000 \\
\cline { 2 - 4 } & Average Measures & $.781^{\mathrm{c}}$ & .000 \\
\hline \multirow{2}{*}{$\begin{array}{l}\text { Leader-Member } \\
\text { Exchange }\end{array}$} & Single Measures & $.548^{\mathrm{a}}$ & .000 \\
\cline { 2 - 4 } & Average Measures & $.930^{\mathrm{c}}$ & .000 \\
\hline Discretionary Power & Single Measures & $.112^{\mathrm{a}}$ & .000 \\
\cline { 2 - 4 } & Average Measures & $.601^{\mathrm{c}}$ & .000 \\
\hline \multirow{2}{*}{ Job Satisfaction } & Single Measures & $.321^{\mathrm{a}}$ & .000 \\
\cline { 2 - 4 } & Average Measures & $.703^{\mathrm{c}}$ & .000 \\
\hline
\end{tabular}

\subsubsection{Internal construct validity through inter-item correlations and co- variances}

It is used whether a scale or test measures the construct accurately. It measures what it claims to be measuring. Convergent and Discriminant validity are subcategories of construct validity. They collectively demonstrate construct validity. Construct validity cannot be established without establishing them. The results of convergent and discriminate validity are shown in table below.

Table 3: Convergent validity

\begin{tabular}{|l|l|}
\hline Variables Culture & AVE \\
\hline $\begin{array}{l}\text { National } \\
\text { Dimensions Organizational }\end{array}$ & 0.64 \\
\hline $\begin{array}{l}\text { Perceived } \\
\text { Support }\end{array}$ & 0.75 \\
\hline Leader-Member Exchange & 0.75 \\
\hline Discretionary Power Job & 0.78 \\
\hline $\begin{array}{l}\text { Transgender } \\
\text { Satisfaction }\end{array}$ & \\
\hline
\end{tabular}


Table 4: Discriminant validity

\begin{tabular}{|c|c|c|c|c|c|}
\hline & NC & LMX & POS & DP & TJS \\
\hline NC & 0.84 & & & & \\
\hline LMX & 0.17 & 0.80 & & & \\
\hline POS & 0.00 & 0.24 & 0.86 & & \\
\hline DP & 0.03 & 0.29 & 0.23 & 0.87 & \\
\hline TJS & 0.04 & 0.59 & 0.20 & 0.33 & 0.88 \\
\hline
\end{tabular}

Table 3 shows the convergent value that is Average Variance Extracted (AVE) and table 4 shows discriminant validity that explains square root of Convergent validity. The AVE value must be at least 0.5 , and is greater than square of each correlation. Average Variance Extracted (AVE) was also examined to further test the discriminant validity of measures. Using the procedure of (Fornell \& Larcker, 1981), the square root of AVE ranged from 0.72 to 0.93 and average 0.81 . These results suggest that the variance exceeded the amount of measurement error related to each construct's items. Further, the square root of AVE for any two constructs exceeded their correlation, which suggests that the measures capture distinct constructs. Cumulatively, these findings indicate that national culture dimensions, perceived organizational support, leader member exchange, discretionary power and job satisfaction all have acceptable internal construct validity.

\subsubsection{Inter-item correlations}

It is a way of conducting an item analysis of a set of test questions. It examines relation of score on one item to score on all other items in a scale. The average inter-item correlation for a set of items should be between the range of 0.20 and 0.40 . It indicates that while the items are similar but hold enough distinguish difference in a way that items are not isomorphic in nature. When value is less than 0.20 then the items may not be representative of the same content domain. If value is greater than 0.40 , the items may be only capturing a little fraction of construct. The tables given below show the inter-item correlations for the variables used in the study. The tables show how each item of the study correlates to all other items. All 
the items show correlation with one another, however there are some lower values as well representing that these items have less correlation with each other but considered acceptable.

Table 5a: Inter-Item Correlation Matrix (National Culture)

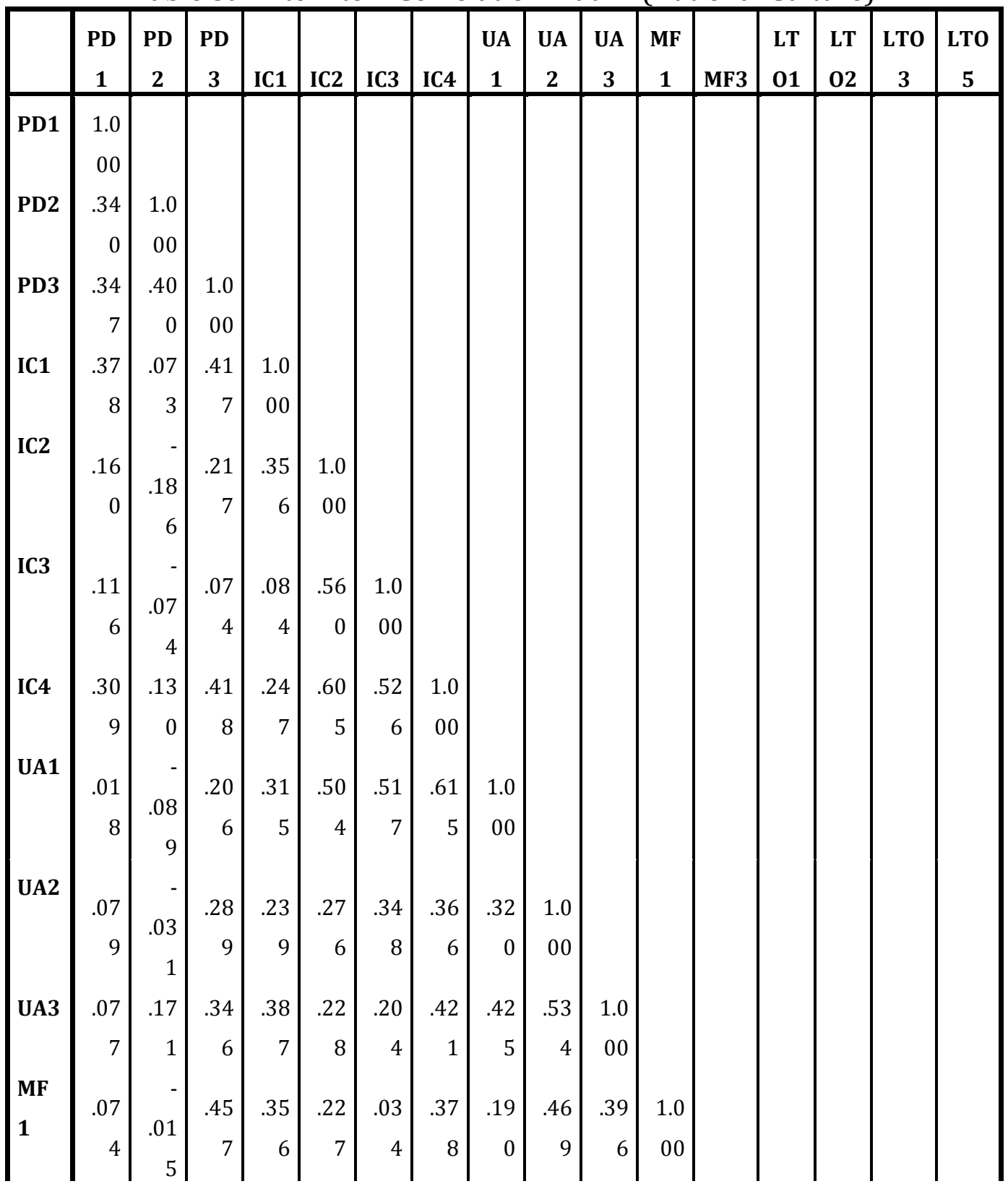


Determinants of transgender job satisfaction: Measuring the validity and reliability of the constructs

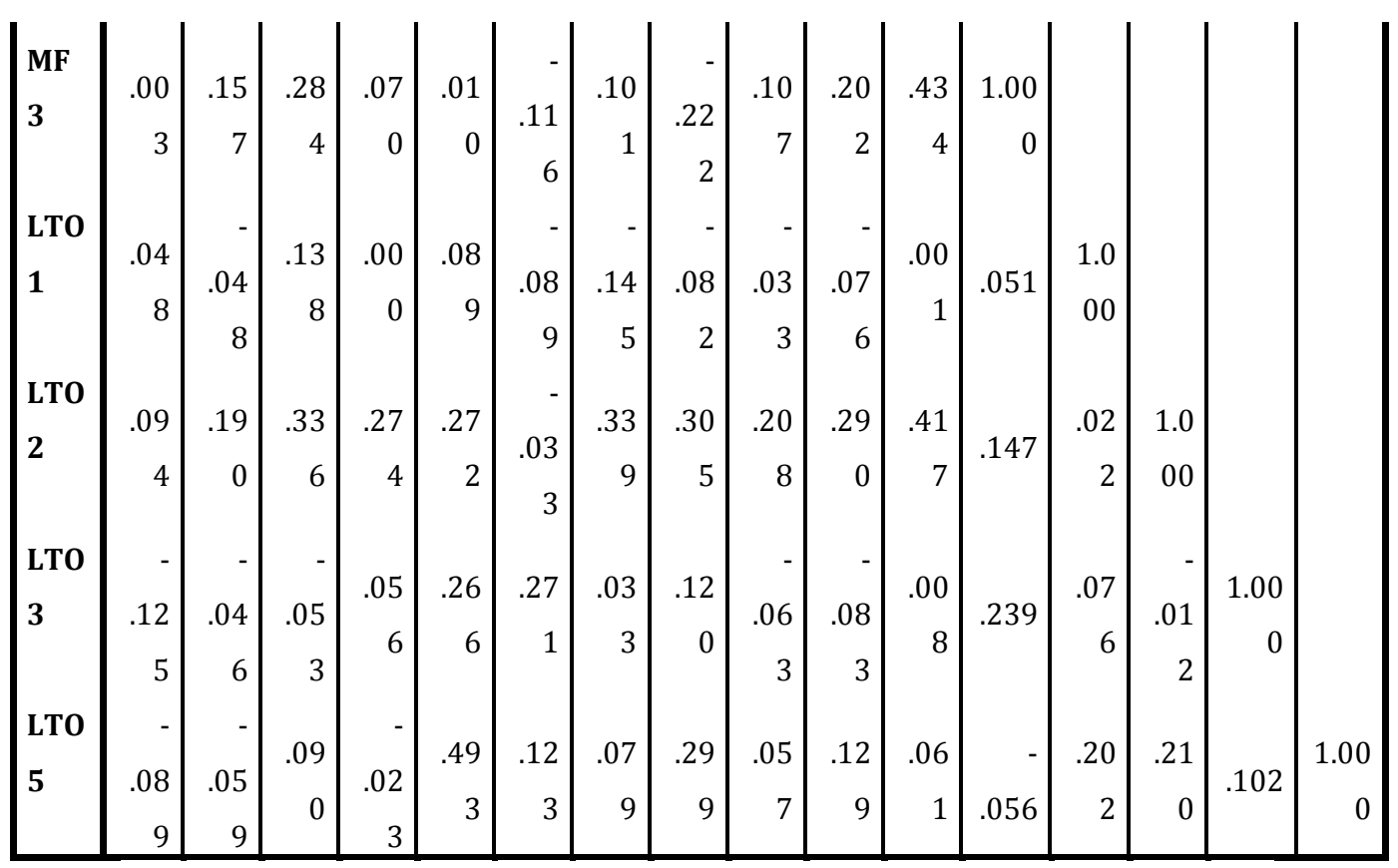

Table 5b: Inter-Item Correlation Matrix (Perceived

\begin{tabular}{|l|r|r|r|r|}
\hline & Organizational Support) \\
\hline POS1 & 1.000 & \multicolumn{1}{|c|}{ POS2 } & \multicolumn{1}{c|}{ POS3 } & P0S4 \\
POS2 & .593 & & & \\
POS3 & .323 & .000 & & \\
POS4 & .662 & .466 & 1.000 & \\
\hline
\end{tabular}

Table 5c: Inter-Item Correlation Matrix (Leader-Member Exchange)

\begin{tabular}{|l|r|c|c|c|c|c|c|c|c|c|c|}
\hline & & & & & & & & & & L & \\
& LMX & LMX & LMX & LMX & LMX & LMX & LMX & LMX & LMX & X & \\
& $\mathbf{1}$ & $\mathbf{2}$ & $\mathbf{3}$ & $\mathbf{4}$ & $\mathbf{5}$ & $\mathbf{6}$ & $\mathbf{7}$ & $\mathbf{8}$ & $\mathbf{9}$ & $\mathbf{1 0}$ & LMX11 \\
\hline LMX1 & $\begin{array}{r}1.00 \\
\text { LMX2 }\end{array}$ & & & & & & & & & & \\
& 0 & & & & & & & & & & \\
1.00 & & & & & & & & &
\end{tabular}


Jhss, Vol. 9, No. 1, January to June, 2018

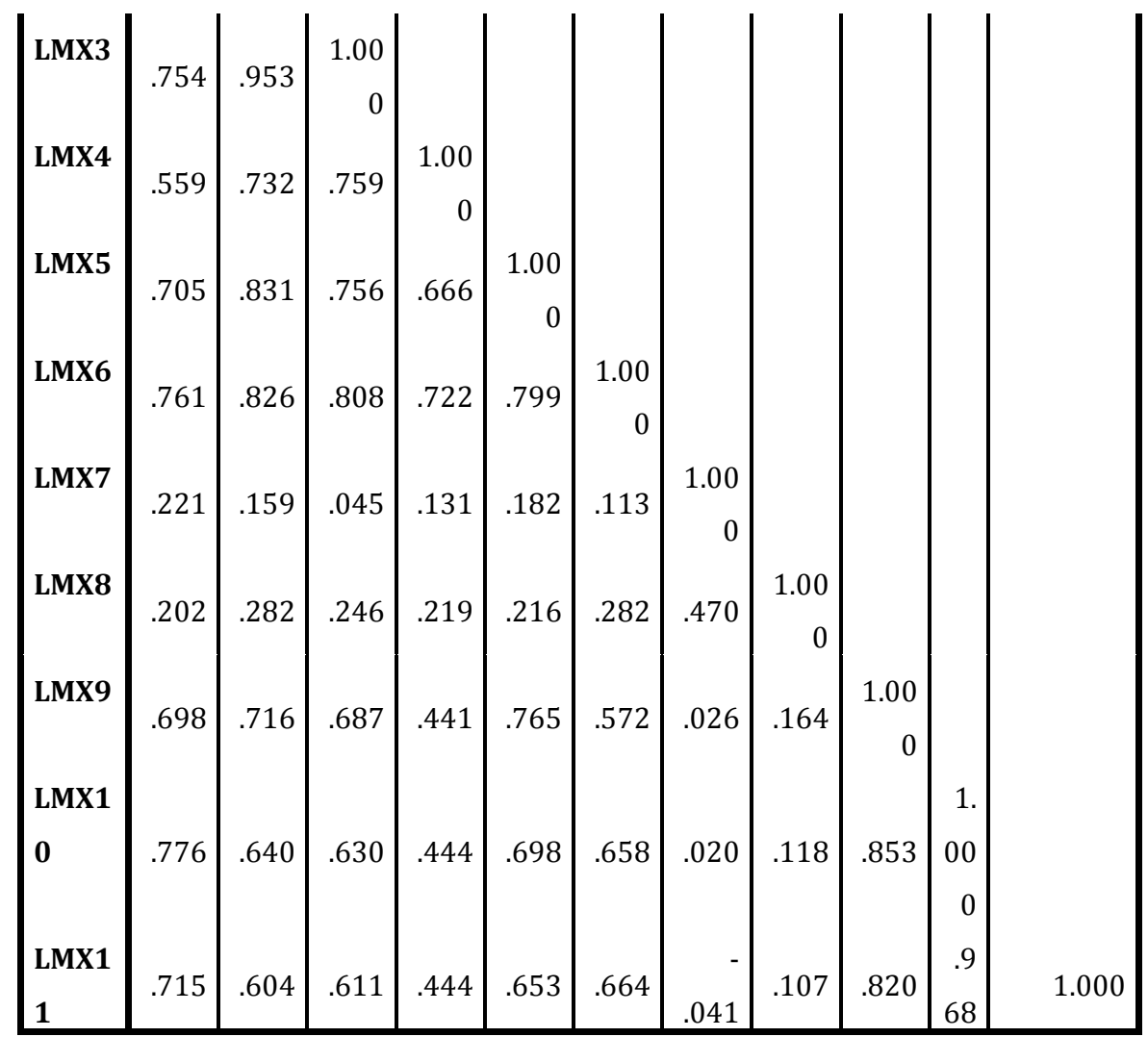

Table 5d: Inter-Item Correlation Matrix (Discretionary Power)

\begin{tabular}{|l|r|r|r|r|r|r|r|r|r|r|r|r|}
\hline & M1 & M2 & M3 & C1 & C2 & C3 & SD1 & SD2 & SD3 & I1 & I2 & I3 \\
\hline $\mathbf{M}$ & 1.00 & & & & & & & & & & & \\
$\mathbf{1}$ & 0 & & & & & & & & & & & \\
$\mathbf{M}$ & .414 & 1.00 & & & & & & & & & & \\
$\mathbf{2}$ & & 0 & & & & & & & & & & \\
$\mathbf{M}$ & .345 & .944 & 1.00 & & & & & & & & & \\
$\mathbf{3}$ & & & 0 & & & & & & & & & \\
C1 & .500 & .134 & .160 & 1.00 & & & & & & & & \\
C2 & .451 & .337 & .372 & .508 & 1.00 & & & & & & & \\
C3 & .265 & .432 & .498 & .373 & .603 & 1.00 & & & & & &
\end{tabular}




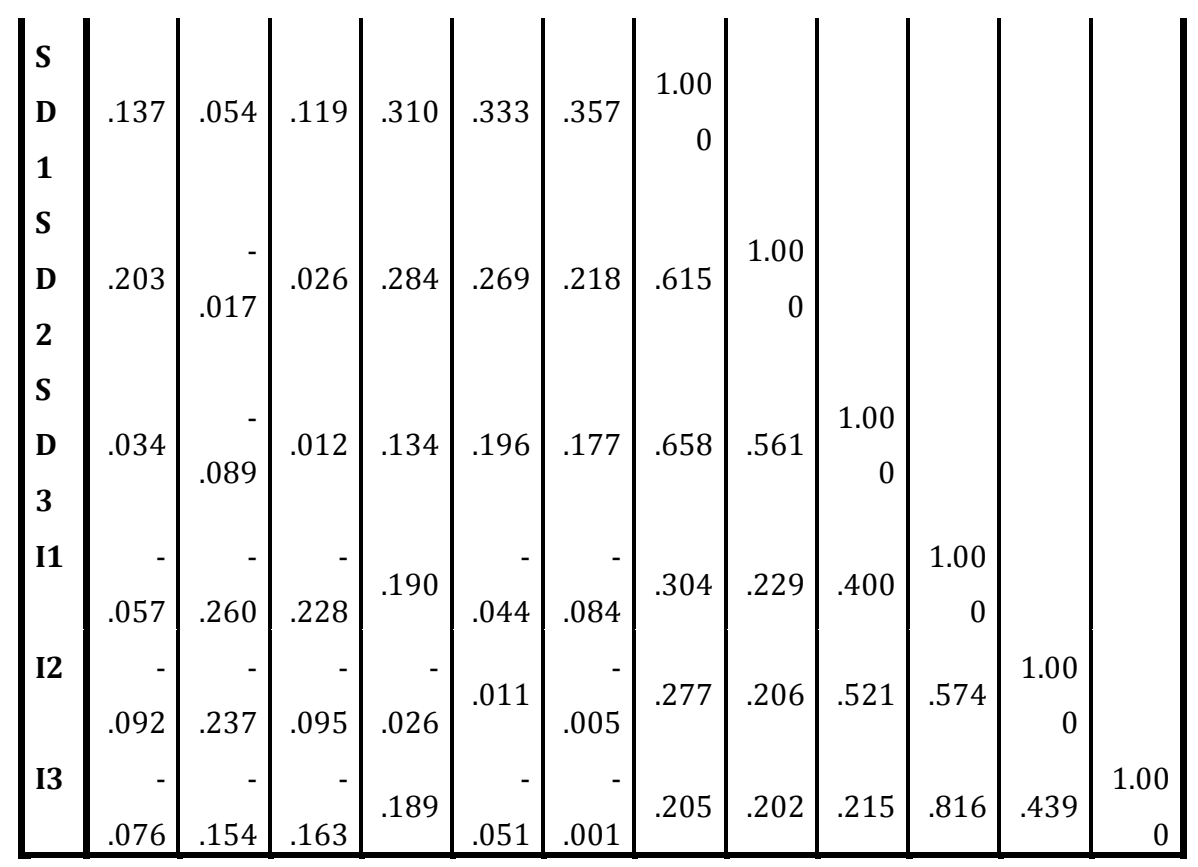

Table 5e: Inter-Item Correlation Matrix (Transgender Job Satisfaction)

\begin{tabular}{|l|r|r|r|r|r|}
\hline & \multicolumn{1}{|c|}{ TJS1 } & \multicolumn{1}{|c|}{ TJS2 } & \multicolumn{1}{|c|}{ TJS3 } & \multicolumn{1}{|c|}{ TJS4 } & \multicolumn{1}{|c|}{ TJS5 } \\
\hline TJS1 & 1.000 & & & & \\
TJS2 & .822 & 1.000 & & & \\
TJS3 & .107 & .110 & 1.000 & & \\
TJS4 & .220 & .049 & .290 & 1.000 & \\
TJS5 & .799 & .786 & .114 & .189 & 1.000 \\
\hline
\end{tabular}

3.2.5 Criterion-related validity through correlation coefficient

Criterion related validity looks at the degree of correlation between scores of one measurement instrument and a behavior or attitude that the assessment should be related to. If the test has the desired correlation with the criterion then there is sufficient evidence for it. It examines the real association between variables that purportedly are related. It correlates measure with a criterion using the correlation coefficient denoted by ( $r$ ). Correlation is directly proportional to criterion validity. Table 6 shows the results of coefficient (r). 
Table 6: Correlations

\begin{tabular}{|ll|r|r|r|r|r|}
\hline & & AVGNC & AVGLMX & AVGPOS & AVGDP & AVGTJS \\
\hline AVGNC & PC & 1 & & & & \\
& Sig. (2-tailed) & & & & & \\
& $\mathrm{N}$ & 48 & & & & \\
\hline AVGLMX & PC & $.613^{* *}$ & 1 & & & \\
& Sig. (2-tailed) & .000 & & & & \\
& $\mathrm{~N}$ & 48 & 48 & & & \\
\hline AVGPOS & PC & $.303^{*}$ & $.544^{* *}$ & 1 & & \\
& Sig. (2-tailed) & .036 & .000 & & & \\
& $\mathrm{~N}$ & 48 & 48 & 48 & & \\
\hline AVGDP & PC & $.368^{* *}$ & $.564^{* *}$ & $.482^{* *}$ & 1 & \\
& Sig. (2-tailed) & .010 & .000 & .001 & & \\
& $\mathrm{~N}$ & 48 & 48 & 48 & 48 & \\
\hline AVGTJS & PC & $.576^{* *}$ & $.773^{* *}$ & $.448^{* *}$ & $.579^{* *}$ & \\
& Sig. (2-tailed) & .000 & .000 & .001 & .000 & \\
& $\mathrm{~N}$ & 48 & 48 & 48 & 48 & 48 \\
\hline
\end{tabular}

**. Correlation is significant at the 0.01 level (2-tailed).

*. Correlation is significant at the 0.05 level (2-tailed).

\section{DISCUSSION AND CONCLUSION}

Studies on adopting policies for stigmatized group are not much in literature. On the basis of perceived organizational support theory, it was posited that all workers directly perceive high organizational support related to policies for sexual minority employees and indirectly by assessing sexually diverse environment (Pichler, Ruggs, \& Trau, 2017). However, these policies have workable significance because organizational support works in reciprocity as individuals are motivated to exert productive behavior and contribute efforts with full capacity of potential (Kurtessis et al., 2017). To assess the validity and reliability is essential to help decide other researchers whether or not apply the findings and ensure the quality of data (Heale \& Twycross, 2015). The instrument of the current research is adopted after through study of literature review. The analysis shows that the values of Cronbach's Alpha are found acceptable and hence instrument is open for further data collection. The results of internal consistency also met the threshold value. Moreover, experts examined and endorse the face plus content validity of the 
questionnaire. The variables selected for this study has a significant value in organizational setting, moreover the social lab of transgender at workplace is under study area, and hence the results will significantly contribute in the body of knowledge of this specific area. Bell, Özbilgin, Beauregard, \& Sürgevil (2011) argued that proliferation in workforce diversity required different and novice mechanism for voice of sexually oriented employees. This can be significant in order to foster those stigmatized employees who were silence and could ensure openly communication and inclusive environment at workplace. Thus, creating a culture of inclusion would benefit both organizations and stigmatized employees. This would bring all firms to make policies for trans-individuals rather rely on federal legislation. A move towards more inclusive workplace is in a dire need and on the principle of reciprocity this would be useful for organization as well. 


\section{References}

Alexandra Beauregard, T., Arevshatian, L., Booth, J. E., \& Whittle, S. (2018). Listen carefully: transgender voices in the workplace. The International Journal of Human Resource Management, 29(5), 857-884. https://doi.org/10.1080/09585192.2016.1234503

Bell, M. P., Özbilgin, M. F., Beauregard, T. A., \& Sürgevil, O. (2011). Voice, silence, and diversity in 21st century organizations: Strategies for inclusion of gay, lesbian, bisexual, and transgender employees. Human Resource Management, 50(1), 131-146. https://doi.org/10.1002/hrm.20401

Clise, S. M. and L. (2012, September 28). Big Business Increasingly Supports Gay Rights. Harvard Business Review. Retrieved from https://hbr.org/2012/09/big-business-increasingly-supp

Fornell, C., \& Larcker, D. F. (1981). Evaluating Structural Equation Models with Unobservable Variables and Measurement Error. Journal of Marketing Research, 18(1), 39. https://doi.org/10.2307/3151312

Gacilo, J., Steinheider, B., Stone, T. H., Hoffmeister, V., Jawahar, I. M., \& Garrett, T. (2018). The double-edged sword of having a unique perspective: Feelings of discrimination and perceived career advantages among LGBT employees.

Equality, Diversity and Inclusion: An International Journal, 37(3), 298-312. https://doi.org/10.1108/EDI-03-2017-0060

Hair, J. F. (Ed.). (2014). Multivariate data analysis (7. ed., Pearson new internat. ed). Harlow: Pearson.

Heale, R., \& Twycross, A. (2015). Validity and reliability in quantitative studies. Evidence Based Nursing, 18(3), 66-67. https://doi.org/10.1136/eb2015-102129

Holman, E. G., Fish, J. N., Oswald, R. F., \& Goldberg, A. (2018). Reconsidering the LGBT Climate Inventory: Understanding Support and Hostility for LGBTQ Employees in the Workplace. Journal of Career Assessment, 106907271878832. https://doi.org/10.1177/1069072718788324 
ILO. (2013). Discrimination at work on the basis of sexual orientation and gender identity: Results of pilot research, 5 .

Jackson, S. L. (2015). Research Methods and Statistics: A Critical Thinking Approach. Cengage Learning.

Kurtessis, J. N., Eisenberger, R., Ford, M. T., Buffardi, L. C., Stewart, K. A., \& Adis, C. S. (2017). Perceived Organizational Support: A Meta-Analytic Evaluation of Organizational Support Theory. Journal of Management, 43(6), 1854-1884. https://doi.org/10.1177/0149206315575554

Muijs, D. (2010). Doing Quantitative Research in Education with SPSS. SAGE.

Ozturk, M. B., \& Tatli, A. (2016). Gender identity inclusion in the workplace: broadening diversity management research and practice through the case of transgender employees in the UK. The International Journal of Human Resource Management, 27(8), 781-802. https://doi.org/10.1080/09585192.2015.1042902

Pallant, J. (2016). SPSS Survival Manual: A Step by Step Guide to Data Analysis Using IBM SPSS. Allen \& Unwin.

Pichler, S., Ruggs, E., \& Trau, R. (2017). Worker outcomes of LGBT-supportive policies: a cross-level model. Equality, Diversity and Inclusion: An International Journal, 36(1), 17-32. https://doi.org/10.1108/EDI-07-20160058

Schreiber, J. B., Nora, A., Stage, F. K., Barlow, E. A., \& King, J. (2006). Reporting Structural Equation Modeling and Confirmatory Factor Analysis Results: A Review. The Journal of Educational Research, 99(6), 323-338. https://doi.org/10.3200/JOER.99.6.323-338

Sekaran, U. (2003). Research methods for business: a skill-building approach (4th ed). New York: John Wiley \& Sons.

Šerbetar, I., \& Sedlar, I. (2016). Assessing Reliability of a Multi-Dimensional Scale by Coefficient Alpha, 8. 
United Nations. (2016). OHCHR | Combating discrimination based on sexual orientation and gender identity. Retrieved November 24, 2018, from https://www.ohchr.org/en/issues/discrimination/pages/lgbt.aspx

Webster, J. R., Adams, G. A., Maranto, C. L., Sawyer, K., \& Thoroughgood, C. (2018). Workplace contextual supports for LGBT employees: A review, metaanalysis, and agenda for future research. Human Resource Management, 57(1), 193-210. https://doi.org/10.1002/hrm.21873

Wilson, J. (2010). Essentials of Business Research: A Guide to Doing Your Research Project. SAGE. 